\title{
Dose-dependent in vitro effect of recombinant human DNase on rheological and transport properties of cystic fibrosis respiratory mucus
}

\author{
J-M. Zahm*, S. Girod de Bentzmann*, E. Deneuville+, C. Perrot-Minnot**, \\ A. Dabadie + , F. Pennaforte**, M. Roussey ${ }^{+}$, S. Shak ${ }^{++}$E. Puchelle*
}

\begin{abstract}
Dose-dependent in vitro effect of recombinant human DNase on rheological and transport properties of cystic fibrosis respiratory mucus. J-M. Zahm, S. Girod de Bentzmann, E. Deneuville, C. Perrot-Minnot, A. Dabadie, F. Pennaforte, M. Roussey, S. Shak, E. Puchelle. (C)ERS Journals Ltd 1995.

ABSTRACT: Recombinant human deoxyribonuclease (rhDNase) has been demonstrated to reduce the viscosity of purulent cystic fibrosis (CF) respiratory mucus, to improve pulmonary function and to reduce the risk of respiratory tract infectious exacerbations, but its effect on mucus transportability has not so far been investigated.

The dose-dependent effect of rhDNase was analysed in vitro on mucus transport rate (tr) by ciliary activity and by simulated cough (cough transport (ct)), as well as on mucus viscosity and surface properties. Purulent $\mathrm{CF}$ sputa $(n=15)$ were incubated for $30 \mathrm{~min}$ at $37^{\circ} \mathrm{C}$ with either rhDNase at three different concentrations (final concentrations $0.2,2$ or $20 \mu \mathrm{g} \cdot \mathrm{ml}^{-1}$ of mucus) or placebo.

No significant dose-dependent effect of rhDNase on the mucociliary transport rate was observed when the samples were statistically analysed together. However, in the larger group of mucus samples $(n=11)$ with a low initial mucociliary transport rate, the latter was improved at each $r$ DNase concentration $\left(\operatorname{tr}_{0.2}=0.69, \operatorname{tr}_{2}=0.88\right.$ and $\left.\operatorname{tr}_{20}=0.87\right)$ as compared to placebo $\left(\operatorname{tr}_{\mathrm{p}}=\mathbf{0 . 5 8}\right)$. In the smaller group of mucus samples $(n=4)$ with high initial transport rate, a decrease in mucociliary transport rate was observed, particularly at the highest concentration rhDNase assayed, i.e. 20 $\mu \mathrm{g} \cdot \mathrm{ml}^{-1}$ of mucus $\left(\operatorname{tr}_{20}=\mathbf{0 . 5 8}\right)$ as compared to placebo $\left(\operatorname{tr}_{\mathrm{p}}=\mathbf{0 . 8 6}\right)$. The mucus cough transport was increased by rhDNase $\left(\mathrm{ct}_{0.2}=25 \mathrm{~mm}, \mathrm{ct}_{2}=27.5 \mathrm{~mm}\right.$ and $\left.\mathrm{ct}_{20}=31 \mathrm{~mm}\right)$ as compared to placebo $\left(\mathrm{ct}_{\mathrm{p}}=\mathbf{2 3 . 5} \mathrm{mm}\right)$. The alterations in the mucus transport capacity were associated with a decrease in mucus viscosity and an improvement in mucus surface properties.

These results suggest that rhDNase, at concentrations found in respiratory mucus after inhalation of the recommended therapeutic dose, improves both the cough and mucociliary transport of CF mucus samples characterized by a low mucociliary transport rate.

Eur Respir J., 1995, 8, 381-386.
\end{abstract}

*Inserm U314 and **American Memorial Hospital, Reims, France. +Hôpital Pontchaillou, Rennes, France. ${ }^{++}$Genentech, San Francisco, USA.

Correspondence: J-M. Zahm

Inserm U314 CHR Maison Blanche

45, rue Cognacq-Jay

51092 Reims Cedex

France

Keywords: Cough transport

cystic fibrosis

deoxyribonuclease

mucociliary transport

mucus rheology

respiratory mucus

Received: July 11994

Accepted after revision December 291994
Cystic fibrosis (CF) is characterized by a general dysfunction of surface airway epithelial cells and of exocrine glands of the respiratory tract, caused by cystic fibrosis transmembrane conductance regulator (CFTR) mutations. The ion and water transport dysfunctions produce dehydrated and highly viscous mucus, which contributes to a decreased mucociliary transport and accumulation of infected secretions [1]. Due to persistent infection, numerous neutrophils release large amounts of deoxyribonucleic acid (DNA) which contribute to the increased viscous properties of the purulent respiratory mucus $[2,3]$.

It has been reported previously that bovine pancreatic deoxyribonuclease (DNase) reduced the viscosity of lung secretions in vitro $[4,5]$. However, adverse reactions after the inhalation of bovine pancreatic DNase led to this foreign protein no longer being used [6]. A highly purified recombinant human DNase I (rhDNase) was recently produced, and was found to dramatically reduce the viscosity of CF sputum [7]. Multicentre clinical studies demonstrated the safety and efficacy of the short-term and long-term administration of aerosolized rhDNase on the pulmonary function and symptoms of CF patients [8-10]. However, the dose-dependent effect of rhDNase on mucus transportability is still unknown.

We therefore addressed the question of whether rhDNase could improve in vitro mucus transport by ciliary activity and by cough. In association with the transport 
measurements we analysed the dose-dependent effect of rhDNase on the rheological and surface properties of mucus.

\section{Material and methods}

\section{Study subjects}

Fifteen cystic fibrosis patients were included in this study. The median age of the group of patients was 19 yrs (range 6-25 yrs). Nine patients were homozygous for the $\Delta \mathrm{F} 508$ mutation and six were heterozygous. Their vital capacity and forced expiratory volume, expressed as percentage of predicted value (\% pred), ranged between $45-108 \%$ pred (median $=74 \%$ pred) and $18-101 \%$ pred (median $=53 \%$ pred), respectively. The Shwachman score ranged between 45-90 (median=66). To collect respiratory mucus by expectoration, physiotherapy was performed for $30 \mathrm{~min}$ in these patients. Dental cottonwool swabs were placed in the mouth of the patient during expectoration to limit salivary contamination [11]. Twelve of the 15 patients were colonized by Pseudomonas aeruginosa. All mucus samples appeared purulent.

\section{Study design}

After expectoration, each mucus sample was kept at $4^{\circ} \mathrm{C}$ and analysed within $24 \mathrm{~h}$. For analysis, the mucus sample was divided into four aliquots. Each aliquot was incubated for $30 \mathrm{~min}$ at $37^{\circ} \mathrm{C}$, either with placebo $(\mathrm{NaCl}$ $150 \mathrm{mM}+1 \mathrm{mM} \mathrm{CaCl}{ }_{2}=$ control), or with three different concentrations of rhDNase (final concentrations $0.2,2$ or $20 \mu \mathrm{g} \cdot \mathrm{ml}^{-1}$ of mucus). The volume of placebo or rhDNase diluted in placebo which was added to the mucus represented $4 \%$ of the mucus sample volume. It was gently stirred into the mucus for $5 \mathrm{~s}$. After the incubation period, we analysed the viscoelastic and surface properties of each mucus aliquot. We also measured the mucus transport by ciliary activity (frog palate model) and by cough (simulated cough machine)

\section{Methods}

\section{Viscoelastic properties}

The mucus viscoelastic properties were analysed by using a controlled stress rheometer (Carri-Med) equipped with a cone-plate geometry [12]. The angle between the cone and the plate was 0.017 radian, and the sample volume required was $20 \mu \mathrm{l}$. The measurements were carried out at $25^{\circ} \mathrm{C}$ using the creep test technique. A constant stress of $10 \mathrm{~Pa}$ was applied to the sample, and the resultant strain was recorded versus time. When a steady flow was achieved, the applied stress was suppressed and the recovery angle $(\gamma)$ of the strain, representative of the mucus elasticity, was measured. The slope of the strain versus time curve represented the shear rate applied to the mucus sample. The ratio shear-stress/shear-rate and the ratio shear stress/shear strain allowed us to calculate the mucus viscosity and the mucus elastic modulus, respectively.

\section{Surface properties}

The mucus surface properties were analysed by measuring the contact angle of a $20 \mu \mathrm{l}$ drop of mucus, which was deposited on a glass slide in a small chamber with $100 \%$ relative humidity. An image analysis technique was used to measure the angle between the tangent to the mucus-air interface and the horizontal at the contact point of the drop of mucus with the glass slide [13].

\section{Mucus transport by cough}

The experiments were performed using the cough machine developed by KING et al. [14]. A tank of $6 l$ volume was used as reservoir for pressurized air, and was connected through a solenoid valve to a plastic tube simulating the trachea. The floor of this tube was a glass slide, on which the drop of mucus used for contact angle measurement was deposited. A cough was simulated by opening the solenoid valve, releasing the pressurized air through the model trachea in which the airflow was $6 l \cdot \mathrm{s}^{-1}$. The distance travelled by the mucus under the effect of the airflow was measured, and represented the mucus cough transport. According to the volume of mucus collected, one or two measurements were made for each aliquot.

\section{Mucus transport by ciliary activity}

In vitro measurements of the mucus transport by the ciliary activity were made using the frog palate technique [15]. Isolated palates from frogs (Rana esculenta) were placed in a plexiglass chamber at a controlled temperature $\left(25^{\circ} \mathrm{C}\right)$ and in $100 \%$ relative humidity. After $24 \mathrm{~h}$, endogenous mucus secretion of the isolated palate was exhausted but the cilia remained active. This depleted palate was used to measure the mucociliary transport both of the control frog mucus and the $\mathrm{CF}$ respiratory mucus. A drop of mucus $(1 \mu \mathrm{l})$ taken from the palate of a recently killed frog was placed on the depleted palate, and its transport velocity was measured by following the velocity of a calibrated aluminium disc $(600$ $\mu \mathrm{m}$ in diameter) placed on the mucus drop. Thereafter, the transport velocity of the $\mathrm{CF}$ respiratory mucus aliquots was measured in the same manner, and the results were expressed as relative transport rate (tr) corresponding to the ratio of $\mathrm{CF}$ respiratory mucus transport rate to the control frog mucus transport rate, both being measured at the same time on the same depleted frog palate. Three measurements were made for each mucus aliquot. 


\section{Total DNA content measurement}

Mucus DNA content was determined by a modification of the diaminobenzoic acid (DABA) assay [16] developed by KISSANE and RoBINS [17]. Briefly, mucus was diluted tenfold with diluent (hydroxyethylpiperazine ethanesulphonic acid $25 \mathrm{mM}$ (HEPES,) $1 \mathrm{mg} \cdot \mathrm{ml}^{-1}$ bovine serum albumin, (BSA) $4 \mathrm{mM} \mathrm{CaCl}, 0.05 \%$ polysorbate 20 , and $0.01 \%$ thimerasol, $\mathrm{pH} 7.5$ ) and incubated at $60^{\circ} \mathrm{C}$ for $1 \mathrm{~h}$.

Fifty microlitres of the diluted mucus were incubated in microtitre plate wells with $50 \mu$ of $20 \% 3,5-$ diaminobenzoic acid hydrochloride solution at $60^{\circ} \mathrm{C}$ for $1 \mathrm{~h}$, and then $50 \mu \mathrm{l}$ of $5 \mathrm{~N} \mathrm{HCl}$ was added to stop the reaction. Fluorescence was measured in a microtitre plate fluorometer (with $390 \mathrm{~nm}$ excitation and $530 \mathrm{~nm}$ emission filters). Salmon testes DNA (Sigma) was used to establish the standard curve. This assay, which measures total DNA concentration independent of its length, was performed on 11 of the 15 samples (the volume was too small for four samples).

\section{Statistical analysis}

All the data are expressed as a median value and interquartile range. The Spearman correlation test was used to relate the DNA content to the rheological and surface properties of mucus. The nonparametric KruskalWallis test was used to analyse the dose-dependent effect of rhDNase on the rheological and functional properties of mucus. The nonparametric Wilcoxon test was used to compare the control mucus with the DNase-treated mucus. A p-value of less than 0.05 was considered as significant.

\section{Results}

The DNA content in the sputum samples ranged 2.4$19.5 \mathrm{mg} \cdot \mathrm{ml}^{-1}$ (median $8.5 \mathrm{mg} \cdot \mathrm{ml}^{-1}$ ) and was significantly correlated to the viscosity and the elastic modulus of the mucus (fig. 1): the higher the DNA content, the higher the viscosity $(r=0.82 ; \mathrm{p}<0.002)$ and the higher the elastic modulus $(r=0.84 ; \mathrm{p}<0.002)$ of the respiratory mucus.

Compared to control, a significant decrease in the mucus viscosity was observed when the samples were incubated with rhDNase. Nevertheless, no significant difference was obtained between the effect of each concentration of rhDNase (fig. 2a). The decrease in mucus viscosity observed at each rhDNase concentration was significantly correlated to the initial mucus DNA content $(\mathrm{r}=0.85 ; \mathrm{p}<0.01)$ : the higher the DNA content, the larger the decrease in mucus viscosity. No significant dose-dependent effect of rhDNase was observed on the mucus elastic modulus. However, for each rhDNase concentration the mucus contact angle was significantly decreased as compared to control (fig. $2 b$ ).

The mucus cough transport was significantly improved in a dose-dependent way when incubated in the presence of the different concentrations of rhDNase (fig. $3 a)$. Compared to control $(23.5 \mathrm{~mm})$, incubation with
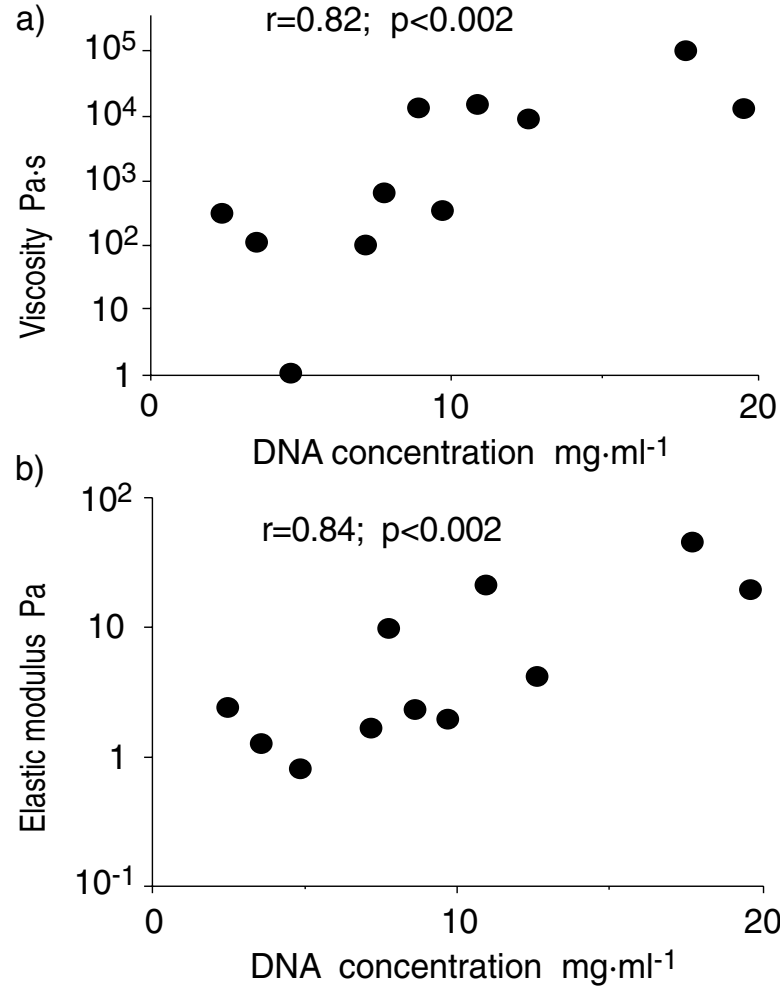

Fig. 1. - The Spearman regression was used to test the relationship between the mucus rheological properties and the deoxyribonucleic acid (DNA) content. The mucus DNA concentration was significantly correlated to mucus viscosity (a) and to mucus elastic modulus (b).

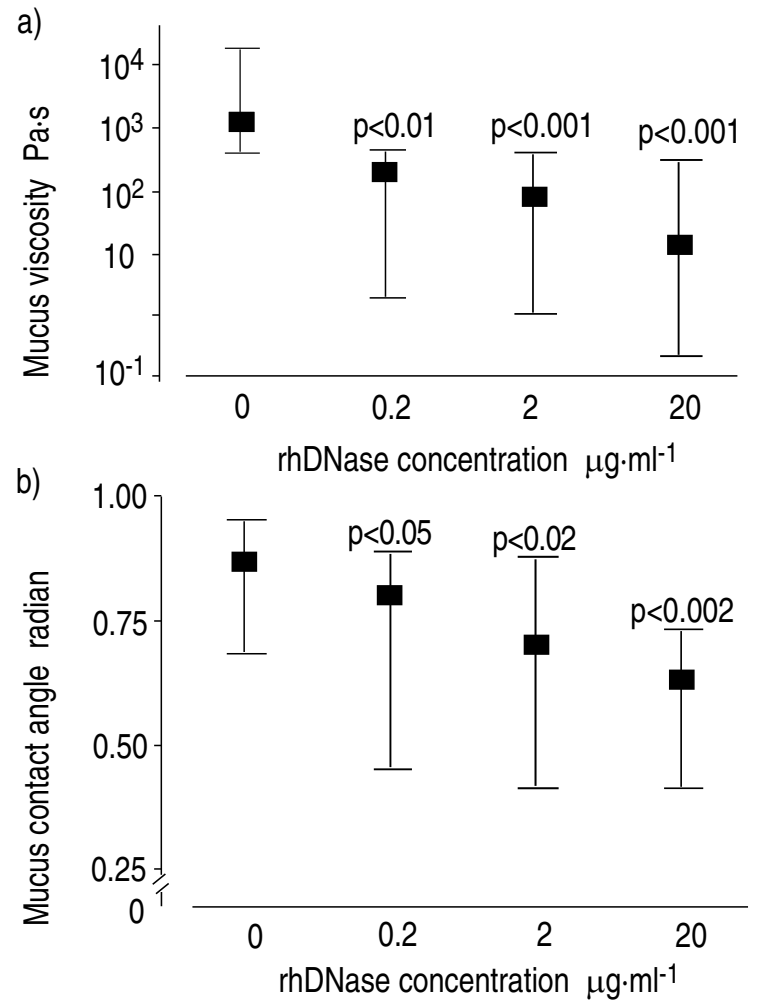

Fig. 2. - Dose-dependent effect of recombinant human deoxyribonuclease (rhDNase) on the rheological and physical properties of mucus. a) The mucus viscosity; and b) the mucus contact angle were significantly lower at rhDNase concentrations of $0.2,2$ and $20 \mu \mathrm{g} \cdot \mathrm{ml}^{-1}$ of mucus, compared to the control. The differences were tested by the nonparametric Wilcoxon test and values represent median and interquartile range. 
rhDNase at a concentration of 2 and $20 \mu \mathrm{g} \cdot \mathrm{ml}^{-1}$ of $\mathrm{mu}-$ cus led to a significant ( $\mathrm{p}<0.05$ and $\mathrm{p}<0.01$, respectively) increase in mucus cough transport (27.5 and 31.0 $\mathrm{mm}$, respectively). The incubation with rhDNase at a concentration of 2 or $20 \mu \mathrm{g} \cdot \mathrm{ml}^{-1}$ of mucus significantly increased the mucus cough transport as compared to the mucus cough transport observed with rhDNase at 0.2 $\mu \mathrm{g} \cdot \mathrm{ml}^{-1}$ of mucus $(\mathrm{p}<0.05$ and $\mathrm{p}<0.0007$, respectively). In addition, rhDNase at $20 \mu \mathrm{g} \cdot \mathrm{ml}^{-1}$ of mucus significantly increased the cough transport as compared to rhDNase at $2 \mu \mathrm{g} \cdot \mathrm{ml}^{-1}$ of mucus $(\mathrm{p}<0.0009)$.

No significant improvement in mucus transport by ciliary activity was observed in response to rhDNase when the mucus transport rates were analysed as a whole (fig. 3b). However, when we plotted the percentage change of mucociliary transport rate measured before and after incubating the mucus samples with the different rhDNase concentrations versus the initial mucociliary transport rate, we observed that the response to rhDNase was apparently related to the initial mucus transport rate (fig, 4). In fact, two groups could be identified: 1) one larger group of mucus samples $(n=11)$ characterized by an initial mucociliary transport rate ranging $0.4-0.7$, which were always improved by the rhDNase; and 2) another smaller group of mucus samples

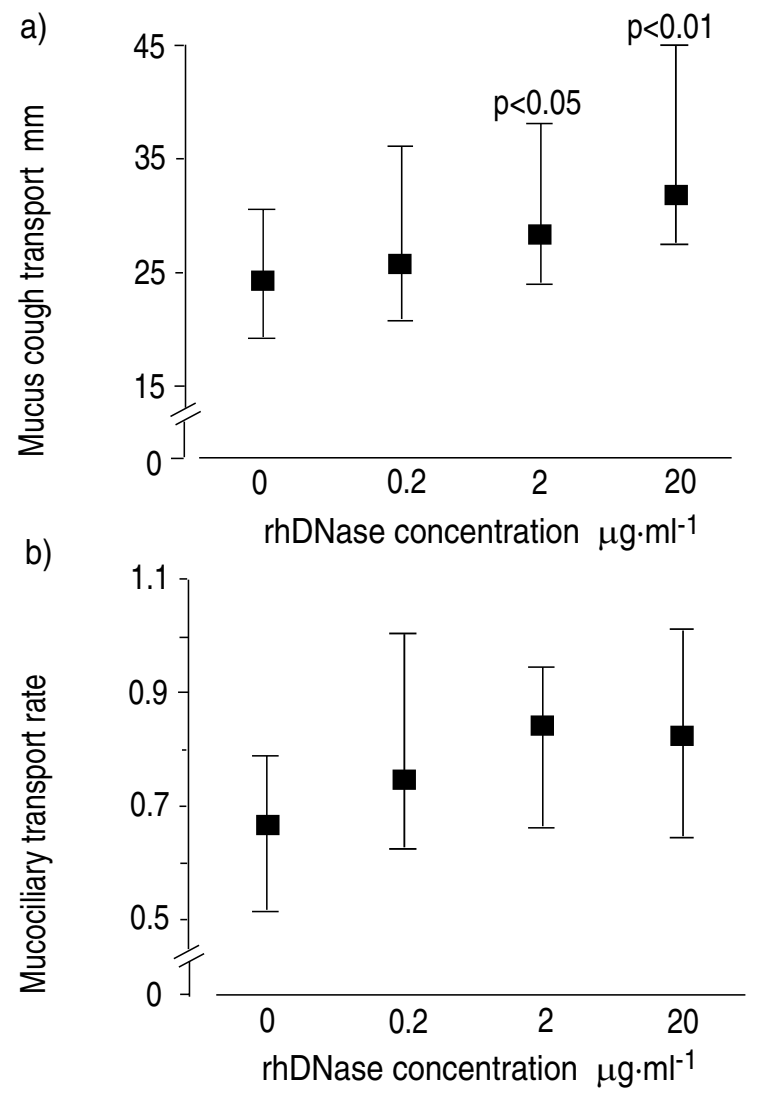

Fig. 3. - Dose-dependent effect of recombinant human deoxyribonuclease (rhDNase) on the in vitro mucus transport. a) The nonparametric Wilcoxon test showed a significant increase in cough transport when the mucus samples were incubated with rhDNase concentrations of 2 and $20 \mu \mathrm{g} \cdot \mathrm{ml}^{-1}$ of mucus. b) No significant dosedependent effect of rhDNase on the relative mucociliary transport rate was observed. Values represent, median and interquartile range. Note that vertical axes are cut off from zero.

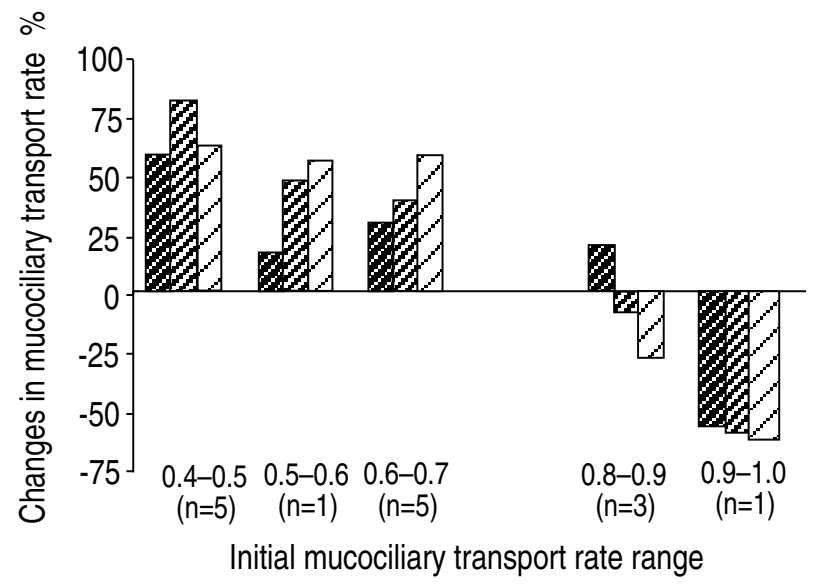

Fig. 4. - Relationship between the change in mucociliary transport rate in vitro (\%) after recombinant human deoxyribonuclease (rhDNase) treatment and the initial mucociliary transport rate (before treatment). For more clarity, the individual changes were grouped in each 0.1 interval. The transport capacity of the mucus samples $(n=11)$ characterized by a low initial mucociliary transport rate, $0.4-0.7$ was significantly improved by rhDNase $(\mathrm{p}<0.001)$, whereas the transport capacity of the mucus samples $(n=4)$, characterized by a high initial mucociliary transport rate, $(0.8-1.0)$ was significantly depressed $(\mathrm{p}<0.05)$, particularly at the highest rhDNase concentration. $\square$ : rhDNase 0.2 $\mu \mathrm{g} \cdot \mathrm{ml}{ }^{-1} ; \square$ : rhDNase $2 \mu \mathrm{g} \cdot \mathrm{ml}^{-1} ; \square$ : rhDNase $20 \mu \mathrm{g} \cdot \mathrm{ml}^{-1}$.

$(n=4)$ characterized by an initial mucociliary transport rate higher than 0.8 , in which higher rhDNase concentrations, $>2 \mu \mathrm{g} \cdot \mathrm{ml}^{-1}$ of mucus, always depressed transport rate. In these, a low concentration of rhDNase $(0.2$ $\mu \mathrm{g} \cdot \mathrm{ml}^{-1}$ of mucus) sometimes accelerated transport rate.

In both groups, a significant dose-dependent effect of rhDNase was observed. The mucociliary transport rate was significantly improved $(\mathrm{p}<0.001)$ in the larger group of patients with a low initial mucociliary transport rate, whereas it was significantly $(\mathrm{p}<0.05)$ decreased in the smaller group of patients with a high initial mucociliary transport rate. It is noteworthy that the percentage change of the mucociliary transport rate after incubation with 2 or $20 \mu \mathrm{g}$ of rhDNase per $\mathrm{ml}$ of mucus was significantly $(\mathrm{p}<0.01)$ and negatively correlated $(\mathrm{r}=-0.69$ and $\mathrm{r}=-0.63$, respectively) with the initial mucociliary transport rate: the higher the initial mucociliary transport rate, the lower the increase after rhDNase treatment. This difference in response to rhDNase could not be related to the DNA content or to the viscosity of the native mucus, which were not significantly different in the two groups of patients.

\section{Discussion}

The present study demonstrates that rhDNase significantly decreased the CF respiratory mucus viscosity in vitro in a dose-dependent way. In association with the viscosity decrease, a significant improvement in the mucus transport by the cough was observed. The improvement by rhDNase of mucus transport by ciliary activity was only evident when the mucus samples were characterized by a depressed initial transport rate.

Large amounts of DNA (2.4-19.5 $\left.\mathrm{mg} \cdot \mathrm{ml}^{-1}\right)$ were present in the mucus samples analysed in our study, and were in the range of the amounts reported in previous 
studies [2,3]. We have shown that the increase in mucus DNA content is associated with an increase in mucus viscosity and mucus elastic modulus. This increase in mucus rheological properties may be related to the high molecular weight of DNA. However, other biochemical factors, such as proteins, glycoproteins and lipids, are involved in the control of the rheological properties of CF mucus [18]. In addition, it has recently been reported that filamentous actin is contained in CF mucus and might also contribute to its thickness [19]. The dramatic ability of rhDNase to reduce mucus viscosity is related to the mucus DNA content, indicating that DNA is a major factor responsible for the increased viscosity of purulent mucus. Although a significant relationship has been demonstrated between the mucus DNA content and the elastic modulus, we could not demonstrate any significant change in the elastic modulus after rhDNase treatment. This is probably due to the fact that a high value of the calculated elastic modulus was representative of a low measured recoverable strain which remained low after rhDNase, resulting in any change in the elastic modulus.

We analysed the effect of rhDNase on the mucus surface properties by measuring the mucus contact angle. We observed that rhDNase induced a significant decrease in the mucus contact angle, which reflects a decrease in mucus surface tension. A decrease in the surface tension of mucus is generally associated with a decrease in the adhesive properties of the mucus and a parallel increase in the transport capacity by ciliary activity and by cough [20]. The improvement in the mucus surface properties cannot be explained by a direct effect of the rhDNase surface tension, since the surface tension of rhDNase was similar to the surface tension of the control solution (data not shown). Two mechanisms could be involved in the decrease in mucus surface properties due to DNA fragmentation by rhDNase: 1) a direct alteration of the mucus surface properties induced by smaller DNA molecules; and 2) a recovery of surface active molecules, such as lipids, which might be dissociated from DNA [21]. Surface active molecules, such as phospholipids, play an important role in mucus adhesive properties [20].

The increase in CF respiratory mucus viscosity is frequently associated with decreased cough transport and decreased ciliary transport [20]. The effectiveness of the cough transport is strongly dependent on the mucus viscosity and on the mucus surface properties: low viscous and adhesive properties promote mucus transport by cough [22]. A decrease in the mucus viscosity and in the mucus contact angle by rhDNase is associated with a significant dose-dependent increase in mucus transport by cough: the higher the rhDNase concentration, the more efficient the mucus transport by cough. Thus, these in vitro results suggest that rhDNase may improve cough clearance. However, the effect of rhDNase on mucus transport by ciliary activity appears to vary according both to the rhDNase concentration and the initial mucus transport rate. Our results demonstrate that mucus samples with an abnormally low initial mucociliary transport capacity (in the range $0.4-0.7$ ) were always improved when incubated with rhDNase, which is the case for $75 \%$ of the CF patients involved in this study. Mucus samples having an initial mucociliary transport capacity higher than 0.8 show impairment in their mucociliary transport capacity after being incubated with a high rhDNase concentration (up to $20 \mu \mathrm{g} \cdot \mathrm{ml}^{-1}$ of rhDNase per ml of mucus). It is noteworthy that only one mucus sample out of 15 had a depressed mucociliary transport rate when incubated with rhDNase at 0.2 $\mu \mathrm{g} \cdot \mathrm{ml}^{-1}$ of mucus. This impairment may be explained by an excessive decrease in mucus viscosity, which induces a decrease in mucus transport by ciliary activity. We have previously considered that a mucociliary transport rate higher than 0.7 can be considered as normal [15], which corresponds in the present work to the limit value for which the response of mucociliary transport rate to rhDNase becomes negative.

It is widely acknowledged that there is no simple linear relationship between respiratory mucus viscosity and mucociliary transport rate. In fact, respiratory mucus might be characterized by an optimal range of viscosity for optimal mucociliary transport [23]. A very high viscosity of mucus decreases the ciliary beating frequency, whereas mucus with low viscosity induces a decrease in the mucus transport rate without any alteration of the ciliary beating frequency. However, in addition to the improvement in the viscosity and/or surface properties of mucus, a direct effect of rhDNase on the ciliary beating frequency could also explain the improvement in the mucociliary transport rate. This hypothesis should be further investigated.

Clinical studies on administration of aerosolized rhDNase in patients with cystic fibrosis have been undertaken using doses up to $10 \mathrm{mg}$ three times a day [8-10]. The mean value of rhDNase concentrations in the respiratory mucus $15 \mathrm{~min}$ after aerosolization of the recommended therapeutic $2.5 \mathrm{mg}$ dose has been reported to be $2.9 \mu \mathrm{g} \cdot \mathrm{ml}^{-1}$ of mucus [24] and it is, therefore, in the range of the concentrations that have been shown to be efficient in the present study. An improvement in mucus clearability due to this enzyme therapy could explain the improvement in the pulmonary function, the reduction in infectious exacerbations, and the perception of well-being in treated cystic fibrosis patients [8].

\section{References}

1. Galabert C, Jacquot J, Zahm JM, Puchelle E. Relationship between the lipid content and the rheological properties of airway secretions in cystic fibrosis. Clin Chim Acta 1987; 164: 139-145.

2. Chernick WS, Barbero GJ. Composition of tracheobronchial secretions in cystic fibrosis of the pancreas and bronchectasis. Pediatrics 1959; 24: 739-745.

3. Potter J, Mathews LW, Lemm J, Spector S. The composition of pulmonary secretions from patients with and without cystic fibrosis. Am J Dis Child 1960; 100: 493-495.

4. Armstrong JB, White JC. Liquefaction of viscous purulent exudates by deoxyribonuclease. Lancet 1950; ii: $739-742$.

5. Chernick WS, Barbero GJ, Eichel HJ. In vitro evaluation 
of effect of enzymes on tracheobronchial secretions from patients with cystic fibrosis. Pediatrics 1961; 27: 589-596.

6. Raskin P. Bronchospasm after inhalation of pancreatic dornase. Am Rev Respir Dis 1968; 98: 597-598.

7. Shak S, Capon DJ, Hellmiss R, Marsters SA, Baker CL. Recombinant human DNase reduces the viscosity of cystic fibrosis sputum. Proc Natl Acad Sci 1990; 87: 9188-9192.

8. Hubbard RC, McElvanet NG, Birrer P, et al. A preliminary study of aerosolized recombinant human deoxyribonuclease I in the treatment of cystic fibrosis. $N$ Engl J Med 1992; 326: 812-815.

9. Ramsey BW, Astley SJ, Aitken MI, et al. Efficacy and safety of short-term administration of aerosolized recombinant human deoxyribonuclease in patients with cystic fibrosis. Am Rev Respir Dis 1993; 148:145151.

10. Ranasinha C, Assoufi B, Shak S, et al. Efficacy and safety of short-term administration of aerosolised recombinant human DNase in adults with stable stage cystic fibrosis. Lancet 1993; 342: 199-202.

11. Puchelle E, Tournier JM, Zahm JM, Sadoul P. Rheology of sputum collected by a simple technique limiting salivary contamination. J Lab Clin Med 1984; 103: 347-353.

12. Puchelle E, Zahm JM, Duvivier C, Didelon J, Jacquot J, Quemada D. Elastothixotropic properties of bronchial mucus and polymer analogs. Biorheology 1985; 22: 415-423.

13. Vaquez-Girod S, Zahm JM, Dionisius JP, Pierrot D, Puchelle E. Automatic measurement of the wetting properties of fluids. Innov Tech Biol Med 1988; 9: 402-412.

14. King M, Brock G, Lundell C. Clearance of mucus by simulated cough. J Appl Physiol 1985; 58: 1776-1782.
15. Puchelle E, Tournier JM, Petit A, et al. The frog palate for studying mucus transport velocity and mucociliary frequency. Eur J Respir Dis 1983; 64: 293-303.

16. Sinicropi D, Prince W, Williams M, et al. Measurement of DNA concentration and length in cystic fibrosis sputum. Pediatr Pulmonol 1994; (suppl. 10): 238.

17. Kissane JM, Robins E. The fluorometric measurement of deoxyribonucleic acid in animal tissues with special reference to the central nervous system. $J$ Biol Chem 1958; 233: 184-188.

18. Pillai RS, Chandra T, Miller F, Lloyd-Still J, Yeates DB. Work of adhesion of respiratory tract mucus. J Appl Physiol 1992; 72 (4): 1604-1610.

19. Vasconcellos CA, Allen PG, Whol ME, Drazen JM, Janmey PA, Stossel TP. Reduction in viscosity of cystic fibrosis sputum in vitro by gelsolin. Science 1994; 263: 969-971.

20. Girod de Bentzmann S, Pierrot D, Fuchey C, Zahm JM, Morançais JL, Puchelle E. Distearoyl phosphatidylglycerol liposomes improve surface and transport properties of CF mucus. Eur Respir J 1993; 6: 1156-1161.

21. Nadziejko CE, Slomiany BL, Slomiany A. Most of the lipid in purulent sputum is bound to mucus glycoprotein. Exp Lung Res 1993; 19: 671-684.

22. King M, Zahm JM, Pierrot D, Vaquez-Girod S, Puchelle E. The role of mucus gel viscosity, spinnability and adhesive properties in clearance by simulated cough. Biorheology 1989; 26: 737-745.

23. Puchelle E, Zahm JM, Quemada D. Rheological properties controlling mucociliary frequency and respiratory mucus transport. Biorheology 1987; 24: 557-563.

24. Sinocropi MW, Prince Ws, Lofgren JA, et al. Sputum pharmacodynamics and pharmacokinetics of recombinant human DNase I in cystic fibrosis. Am J Respir Crit Care Med 1994; 149: A671. 